OPEN ACCESS

Edited by:

Franck Brocherie,

Institut national du sport, de l'expertise et de la performance (INSEP), France

Reviewed by:

Martin Burtscher,

University of Innsbruck, Austria

Sarah J. Willis,

University of Lausanne, Switzerland

${ }^{*}$ Correspondence:

Fabienne Durand

fdurand@univ-perp.fr

Specialty section: This article was submitted to Elite Sports and Performance

Enhancement,

a section of the journal

Frontiers in Sports and Active Living

Received: 03 February 2021

Accepted: 25 March 2021

Published: 26 April 2021

Citation:

Durand F and Raberin A (2021)

Exercise-Induced Hypoxemia in

Endurance Athletes: Consequences

for Altitude Exposure.

Front. Sports Act. Living 3:663674.

doi: 10.3389/fspor.2021.663674

\section{Exercise-Induced Hypoxemia in Endurance Athletes: Consequences for Altitude Exposure}

\author{
Fabienne Durand $^{1 *}$ and Antoine Raberin ${ }^{2}$ \\ ${ }^{1}$ Images Espace Dev, Université de Perpignan Via Domitia, Perpignan, France, ${ }^{2}$ Laboratoire IMS, Université de Bordeaux, \\ Bordeaux, France
}

Exercise-induced hypoxemia $(E I H)$ is well-described in endurance-trained athletes during both maximal and submaximal exercise intensities. Despite the drop in oxygen $\left(\mathrm{O}_{2}\right)$ saturation and provided that training volumes are similar, athletes who experience $\mathrm{EIH}$ nevertheless produce the same endurance performance in normoxia as athletes without $\mathrm{EIH}$. This lack of a difference prompted trainers to consider that the phenomenon was not relevant to performance but also suggested that a specific adaptation to exercise is present in EIH athletes. Even though the causes of EIH have been extensively studied, its consequences have not been fully characterized. With the development of endurance outdoor activities and altitude/hypoxia training, athletes often train and/or compete in this stressful environment with a decrease in the partial pressure of inspired $\mathrm{O}_{2}$ (due to the drop in barometric pressure). Thus, one can reasonably hypothesize that $\mathrm{EIH}$ athletes can specifically adapt to hypoxemic episodes during exercise at altitude. Although our knowledge of the interactions between $\mathrm{EIH}$ and acute exposure to hypoxia has improved over the last 10 years, many questions have yet to be addressed. Firstly, endurance performance during acute exposure to altitude appears to be more impaired in $\mathrm{EIH}$ vs. non-EIH athletes but the corresponding physiological mechanisms are not fully understood. Secondly, we lack information on the consequences of $\mathrm{ElH}$ during chronic exposure to altitude. Here, we (i) review research on the consequences of EIH under acute hypoxic conditions, (ii) highlight unresolved questions about EIH and chronic hypoxic exposure, and (iii) suggest perspectives for improving endurance training.

Keywords: endurance, performance, exercise induced hypoxemia, altitude, $\mathrm{O}_{2}$ desaturation, altitude/hypoxia training, endurance performance

\section{INTRODUCTION}

For many years, cardiovascular responses and muscle metabolism were the only acknowledged limiting factors in exercise performance. However, research has now clearly shown that the respiratory system is far from perfect and does not always have the capacity to meet the demands of intense endurance training (Amann, 2012). Dempsey et al.'s (2020) elegant review analyses the consequences of an "underpowered" respiratory system in endurance-trained athletes, where the excessive strain placed on to the respiratory system (relative to its capacity) leads to several problems, among them a phenomenon called exercise-induced hypoxemia (EIH).

EIH was first described in detail by Dempsey et al. in the 1980s. EIH occurs in some (but not all) endurance-trained athletes performing exercise at sea level (i.e. under normoxic conditions) 
(Dempsey et al., 1984; Dempsey and Wagner, 1999). The phenomenon involves a decrease in arterial oxygen pressure $\left(\mathrm{PaO}_{2}\right)$ and a concomitant drop in arterial oxygen saturation $\left(\mathrm{SaO}_{2}\right)$ between rest and maximal exercise. This hypoxemia is associated with abnormal gas exchange, as reflected by an increase in the alveolo-arterial oxygen pressure difference [ $\mathrm{D}(\mathrm{A}$ a) $\mathrm{O}_{2}$ ] (Dempsey and Wagner, 1999; Prefaut et al., 2000). Since $\mathrm{PaO}_{2}$ and $\mathrm{SaO}_{2}$, together with the hemoglobin concentration, impact the arterial $\mathrm{O}_{2}$ content $\left(\mathrm{CaO}_{2}\right)$, the oxygen $\left(\mathrm{O}_{2}\right)$ supply to the muscles and thus aerobic exercise performance at sea level are impacted. In this context, EIH has attracted interest from sports scientists and physiologists.

\section{EIH DEFINITION AND PHYSIOLOGICAL DETERMINANTS}

Historically, EIH has been studied with invasive measurements of $\mathrm{PaO}_{2}$ and $\mathrm{SaO}_{2}$. The $\mathrm{O}_{2}$ dissociation curve for hemoglobin shows that the fall in $\mathrm{PaO}_{2}$ is linked to $\mathrm{O}_{2}$ desaturation, i.e., a fall in $\mathrm{SaO}_{2}$. Many studies have found that $\mathrm{SaO}_{2}$ ranges from 87 to $94 \%$ in EIH athletes (Powers et al., 1984, 1988; Sheel et al., 2001; Stewart et al., 2003). This involved that the fall of $\mathrm{PaO}_{2}$ is large enough to be located to the sloping part of the Barcroft's curve. Several physiological aspects must be considered in the strict definition of EIH. A fall in $\mathrm{PaO}_{2}$ of at least $10 \mathrm{mmHg}$ between rest and maximal exercise is required, considering that (i) hypoxemia at rest is defined as a fall of $5 \mathrm{mmHg}$ (Préfaut et al., 1988), and (ii) there is a $2-3 \mathrm{mmHg}$ error in the $\mathrm{PaO}_{2}$ measurement during a maximal exercise test (due to the shift in Barcroft's curve with increasing temperature) (Holmgren and McIlroy, 1964). However, $\mathrm{PaO}_{2}$ is not the major determinant of $\mathrm{CaO}_{2}$ as opposed to $\mathrm{SaO}_{2}$, and due to the flat part of the Barcroft's curve some drop in $\mathrm{PaO}_{2}$ could not induced any fall in $\mathrm{SaO}_{2}$. So, $\mathrm{SaO}_{2}$ may be a greater marker to define EIH and the first studies to use $\mathrm{SaO}_{2}$ as a tool for measuring EIH considered $\mathrm{SaO}_{2}<94 \%$ to be abnormal and so set thresholds with a certain margin of error (Powers et al., 1988; Harms and Stager, 1995).

After showing that $\mathrm{VO}_{2}$ max decreases when $\mathrm{SaO}_{2}$ goes below 95\%, Dempsey and Wagner (1999) suggested the following classification: mild $\mathrm{EIH}$ for $\mathrm{SaO}_{2}$ values between 95 and 93\%, moderate EIH for $93-88 \%$, and severe EIH for below $88 \%$. To avoid invasive method, the strong relationship between $\mathrm{SaO}_{2}$ and oxygen pulse saturation values $\left(\mathrm{SpO}_{2}\right)$ at rest and during exercise was considered. The use of pulse oximetry to study EIH was validated (Mollard et al., 2010). Considering interindividual differences in the resting $\mathrm{SpO}_{2}$ values, taking into account (i) the inherent rightward shift of Barcroft's curve during exercise, and (ii) the accuracy of oximeters, Prefaut et al. (2000) defined EIH as a drop in $\mathrm{SpO}_{2}$ of at least $4 \%$ between rest and exercise. Since transient $\mathrm{SpO}_{2}$ drops are typically observed during exercise (Préfaut et al., 1994), the persistent nature of the desaturation must also be taken into account. Hence, the most suitable definition of EIH is a drop of at least $4 \%$ in $\mathrm{SpO}_{2}$ during one or more of the last three steps in an incremental exercise test to exhaustion (Durand et al., 2000; Prefaut et al., 2000). However, steps during a test to exhaustion vary in duration and workload charge, thus to avoid confusion between transient $\mathrm{SpO}_{2}$ drops and EIH a minimum of 3 min of desaturation could be recommend. The magnitude of the fall in $\mathrm{SpO}_{2}$ reported during $\mathrm{EIH}$ is the same as for $\mathrm{SaO}_{2}$ (Grataloup et al., 2005; Stewart and Pickering, 2007; Kyparos et al., 2012; Riganas et al., 2019).

Since the 1990s, several studies showed that athletes with $\mathrm{EIH}$ (EIH athletes) and without (NEIH athletes) with similar training volumes have the same $\mathrm{VO}_{2} \max$ (Legrand et al., 2005; Gaston et al., 2016; Raberin et al., 2019a; Durand et al., 2020). This prompted leading sports scientists to dismiss EIH as not being relevant. However, beyond a $\mathrm{SaO}_{2}$ decrement of $4 \%$ in men and $3 \%$ in women, each additional $1 \%$ decrement results in a $1 \%$ decrement in $\mathrm{VO}_{2} \max$ (Powers et al., 1993; Harms et al., 2000). EIH appears to be a multifactorial phenomenon, with the involvement of ventilation/perfusion mismatch, shunts (intrapulmonary or intracardiac), relative hypoventilation and diffusion limitation (Dempsey and Wagner, 1999). The contribution of each factor is still unclear, although it could partly depend on the intensity of the exercise (Durand et al., 2000). Anyway the purpose of this review is not to discuss around the pathophysiology of EIH but its consequences.

\section{PREVALENCE OF EIH AT SEA-LEVEL}

Few researchers have focused on the prevalence of EIH and an early study reported that $52 \%$ of male athletes with a $\mathrm{VO}_{2} \max$ $>68 \mathrm{ml} \cdot \mathrm{min}^{-1} \cdot \mathrm{kg}^{-1}$ displayed EIH during an incremental exercise test on a cycle ergometer (Powers et al., 1988). Some publication have reported a similar prevalence (Mucci et al., 2000; Connes et al., 2004a; Grataloup et al., 2005; Gaston et al., 2016), whereas others found higher values (60-75\%) (Connes et al., 2004b; Guenette et al., 2004; Connes and Boucher, 2010) or lower values (30-35\%) (Sheel et al., 2000; Alis et al., 2015). Recently, a prevalence of $70 \%$ was reported in a large cohort $(n=79)$ of male athletes with a $\mathrm{VO}_{2} \max$ $>68 \mathrm{ml} . \mathrm{min}^{-1} \cdot \mathrm{kg}^{-1}$ performing a progressive-grade treadmill exercise test to exhaustion (Constantini et al., 2017). Due to a dysanapsis phenomenon with smaller relative lung size, women would be more prone to develop EIH than men (St Croix et al., 1998; Dominelli et al., 2013). Richards et al. (2004) reported that $67 \%$ of young active women $\left(\mathrm{VO}_{2}\right.$ max range: $28-61$ $\mathrm{ml} \cdot \mathrm{kg}^{-1} \cdot \mathrm{min}^{-1}$ ) present EIH during a cycle test to exhaustion.

$\mathrm{EIH}$ is also present at submaximal exercise intensities in some individuals (Dominelli and Sheel, 2018). In this context the "Demand vs. Capacity" theory is unable to explain the phenomenon. There is some evidence to show that hypoxemia during submaximal exercise is the result of relative alveolar hypoventilation while a non-ventilatory mechanism seemed to affect gas exchanges beyond the second ventilatory threshold and thereby enhancing EIH (Durand et al., 2000). The relative hypoventilation is probably at least a result of metabolic changes and different ventilatory responsiveness due to a high level of endurance training (Brooks and Mercier, 1994; Mucci et al., 1998; Granger et al., 2020).

Despite the presence of this large body of evidence, one group of researchers has claimed that EIH is a fallacy because most 
TABLE 1 | Summary findings of studies of ElH athletes exercising under acute hypoxic conditions.

\begin{tabular}{|c|c|c|c|c|}
\hline Study & Participants & Protocol & Exercise test & Results \\
\hline Benoit et al. (2003) & $\begin{array}{l}\text { Five ElH and seven } \\
\text { non-ElH athletes } \\
\text { (runners or cyclists) }\end{array}$ & $\begin{array}{l}\text { Two maximal ramp tests in normoxia } \\
\text { and hypoxia }\left(\mathrm{FiO}_{2}=10.4 \%\right)\end{array}$ & $\begin{array}{l}\text { A cycling maximal ramp test, } \\
\text { with a } 2 \text {-min warm-up and then } \\
\text { increments of } 30 \mathrm{~W} \cdot \mathrm{min}^{-1} \text { in } \\
\text { normoxia and } 15 \mathrm{~W} \cdot \mathrm{min}^{-1} \text { in } \\
\text { hypoxia }\end{array}$ & $\begin{array}{l}\text { A greater drop in HRmax in ElH } \\
\text { athletes than in non-ElH athletes, } \\
\text { despite the lack of a difference in } \\
\mathrm{SaO}_{2} \text { during hypoxic exercise }\end{array}$ \\
\hline Chapman et al. (1999) & $\begin{array}{l}\text { Eight } \mathrm{EIH} \text { and six } \\
\text { non-EIH } \\
\text { endurance-trained } \\
\text { athletes }\end{array}$ & $\begin{array}{l}\text { Two maximal ramp tests in normoxia } \\
\text { and hypoxia }\left(\mathrm{FiO}_{2}=18.7 \%\right)\end{array}$ & $\begin{array}{l}\text { A running maximal ramp test, } \\
\text { with a } 2 \text {-min warm-up and then } \\
\text { a } 2 \% \text { increment in the treadmill's } \\
\text { slope every } 2 \text { min. The speed } \\
\text { remained constant and was } \\
\text { selected by the participant. }\end{array}$ & $\begin{array}{l}\text { A greater drop in } \mathrm{VO}_{2} \text { max } \\
\text { between normoxia and hypoxia } \\
\text { in } \mathrm{ElH} \text { athletes than in non-EIH } \\
\text { athletes (despite a similar } \\
\Delta \mathrm{SaO}_{2} \text { ) during hypoxic exercise. } \\
\text { Whatever the condition, } \mathrm{SaO}_{2} \\
\text { was lower in ElH athletes. }\end{array}$ \\
\hline Gaston et al. (2016) & $\begin{array}{l}\text { Seven EIH and eight } \\
\text { non-ElH athletes } \\
\text { (runners or cyclists) }\end{array}$ & $\begin{array}{l}\text { Two maximal ramp tests in normoxia } \\
\text { and hypoxia }(2150 \mathrm{~m})\end{array}$ & $\begin{array}{l}\text { A cycling maximal ramp test, } \\
\text { with a } 3-\text { min warm-up and then } \\
\text { a } 30 \mathrm{~W} \cdot \mathrm{min}^{-1} \text { increment. }\end{array}$ & $\begin{array}{l}\text { A greater drop in } \mathrm{VO}_{2} \text { max and } \\
\mathrm{HRmax} \text { in ElH athletes than in } \\
\text { non-ElH athletes, despite the } \\
\text { lack of a difference in } \mathrm{SaO}_{2} \\
\text { during hypoxic exercise. }\end{array}$ \\
\hline Grataloup et al. (2007) & $\begin{array}{l}10 \mathrm{EIH} \text { and nine } \\
\text { non-EIH cyclists }\end{array}$ & $\begin{array}{l}\text { Two maximal ramp tests in normoxia } \\
\text { and hypoxia }\left(\mathrm{FiO}_{2}=15.1 \%\right)\end{array}$ & $\begin{array}{l}\text { A cycling maximal ramp test, } \\
\text { with a } 2 \text {-min warm-up and then } \\
\text { a } 0.33 \text { W. } \mathrm{min}^{-1} \cdot \mathrm{kg}^{-1} \text { increment. }\end{array}$ & $\begin{array}{l}\text { Greater drops in } \mathrm{VO}_{2} \text { max, } \\
\mathrm{HR}_{\text {max }} \text {, and } \mathrm{SaO}_{2} \text { in } \mathrm{ElH} \text { athletes } \\
\text { than in non-ElH athletes during } \\
\text { hypoxic exercise }\end{array}$ \\
\hline Raberin et al. (2019a) & $\begin{array}{l}15 \mathrm{ElH} \text { and } 10 \text { non-EIH } \\
\text { athletes (runners and } \\
\text { triathletes) }\end{array}$ & $\begin{array}{l}\text { Two maximal ramp tests in normoxia } \\
\text { and hypoxia }\left(\mathrm{FiO}_{2}=15.3 \%\right)\end{array}$ & $\begin{array}{l}\text { A running maximal ramp test, } \\
\text { with a } 3-\text { min warm-up and then } \\
\text { a } 1 \mathrm{~km} \cdot \mathrm{h}^{-1} \cdot \mathrm{min}^{-1} \text { increment. }\end{array}$ & $\begin{array}{l}\text { A greater drop in } \mathrm{VO}_{2} \text { max, } \\
\mathrm{HRmax} \text {, and } \mathrm{SaO}_{2} \text { in } \mathrm{EIH} \\
\text { athletes than in non-ElH athletes } \\
\text { during hypoxic exercise }\end{array}$ \\
\hline Verges et al. (2005) & $\begin{array}{l}11 \mathrm{EIH} \text { and nine } \\
\text { non-EIH athletes } \\
\text { (triathletes and ski } \\
\text { touring) }\end{array}$ & $\begin{array}{l}\text { Two submaximal exercise in normoxia } \\
\text { and hypoxia }\left(\mathrm{FiO}_{2}=15 \%\right)\end{array}$ & $\begin{array}{l}\text { Cycling for } 10 \text { min at } 40 \% \\
\text { maximum power and (after a } \\
2 \text {-min rest) } 10 \text { min at } 60 \% \\
\text { maximum power. }\end{array}$ & $\begin{array}{l}\text { No differences between } \mathrm{EH} \text { and } \\
\text { non-ElH athletes in } \mathrm{VO}_{2}, \mathrm{PaO}_{2} \text { or } \\
\mathrm{HR} \text { during submaximal exercise. }\end{array}$ \\
\hline
\end{tabular}

studies did not correct hypoxemia considering the rightward shift of the oxy-hemoglobin dissociation curve due to temperature, $\mathrm{CO}_{2}$ and $\mathrm{pH}$ (Scroop and Shipp, 2010). Furthermore, EIH is typically observed during exercises in a laboratory at sea level. On this basis, studies have suggested that EIH reduces performance and induces fatigue (Powers et al., 1988; Romer et al., 2006). However, laboratory conditions do not reflect ecological condition of training or competition, and so $\mathrm{EIH}$ and its consequences have not been studied during real training sessions. As a result, the athletes and coaches have likely underestimated the importance of EIH.

\section{EIH IN ALTITUDE}

Some endurance athletes are required to compete at altitude. For example, trail running has become particularly popular in recent years and the craze is prompting more and more athletes to exercise at moderate altitude, often without acclimatization. In this context of acute exposure to moderate altitude, it has been reported that EIH athletes perform less well than NEIH athletes (Chapman et al., 1999; Gaston et al., 2016; Raberin et al., 2019a). Studies that monitored EIH during an acute exposure to hypoxia were reviewed in Table 1. These studies must have to include a control group in order to investigate the interaction between EIH and exposure to altitude during acute exposure.
The studies were carried out under simulated altitudes of 10003000 m (Chapman et al., 1999; Grataloup et al., 2007; Raberin et al., 2019a), or under naturally hypoxic conditions at $2150 \mathrm{~m}$ (Gaston et al., 2016). All the studies found that the drop in $\mathrm{VO}_{2}$ max during exercise at altitude was greater in EIH athletes. According to some researchers, this drop could be explained (at least in part) by the fact that the EIH athletes had a lower maximal heart rate $\left(\mathrm{HR}_{\max }\right)$ at altitudes of $2150 \mathrm{~m}$ (Gaston et al., 2016), $2400 \mathrm{~m}$ (Raberin et al., 2019a), $3000 \mathrm{~m}$ (Grataloup et al., 2007), and $5000 \mathrm{~m}$ (Benoit et al., 2003). In contrast, Chapman et al. (1999) did not find a difference in $\mathrm{HR}_{\max }$ between EIH and NEIH athletes at an altitude of $1000 \mathrm{~m}$. Some researchers have suggested that the reduction in $\mathrm{VO}_{2} \max$ in $\mathrm{EIH}$ athletes at altitude is associated with the fall in $\mathrm{SaO}_{2}$ observed at sea level (Gavin et al., 1998; Chapman et al., 1999, 2011). Indeed, $\mathrm{SpO}_{2}$ during exercise at altitude is lower in EIH athletes than in NEIH athletes in some studies (Grataloup et al., 2007; Raberin et al., 2019a). A decrease in the ventilatory response to hypoxia can likely explain the lower $\mathrm{SaO}_{2}$ measured in EIH athletes. EIH athletes might fail to have an adequate ventilation during exercise at altitude, which might contribute to hypoxemia (Harms and Stager, 1995; Derchak et al., 2000). However, some studies did not find a relationship between the ventilatory response to hypoxia and $\mathrm{SaO}_{2}$ (Hopkins and McKenzie, 1989; Guenette et al., 2004). Recent studies of the ventilatory response to hypoxia and hypercapnia in $\mathrm{EIH}$ athletes have generated interesting results (Granger et al., 2020). 
Indeed, athletes with the lowest $\mathrm{SpO}_{2}$ during exercise showed a lower ventilatory response to hypercapnia (but not to hypoxia) than athletes with a higher $\mathrm{SpO}_{2}$. This blunted hypercapnic ventilatory response might have consequences on ventilatory acclimatization to altitude. Nevertheless, other studies did not find greater hypoxemia values in EIH athletes (vs. NEIH athletes) during hypoxic exercise (Benoit et al., 2003; Verges et al., 2005; Gaston et al., 2016). In the study by Gaston et al. (2016), the larger decrease in $\mathrm{VO}_{2}$ max in EIH athletes (22 vs. $16 \%$ in $\mathrm{NEIH}$ athletes) could not be wholly explained by a greater reduction in $\mathrm{HR}_{\max }$ and so suggested the involvement of another factor and probably specific adaptation to hypoxia in EIH athletes. More recently, it was reported that EIH athletes displayed exacerbated changes in cerebral deoxygenation and a low limb muscle blood volume at sea level; these results were accentuated by the severity of $\mathrm{O}_{2}$ arterial desaturation, and in contrast to NEIH athletes, were the same in hypoxia and normoxia (Raberin et al., 2019a).

In another way, since the Mexico Olympics, scientists have been particularly interested in altitude training. The traditional "live high, train high" paradigm, i.e., a training camp situated at moderate altitude $(1800-2500 \mathrm{~m})$ is usually implemented two or three times a year (Millet et al., 2010). Historically, it was expected that the altitude-induced hematological response would increase $\mathrm{O}_{2}$ transport and thus aerobic performance back at sea level. However, the nature of other responses requires further investigation. The "live high, train low" (LHTL) altitude training mode was developed in which athletes live at moderate altitude but train at sea level or at low altitude (Levine and Stray-Gundersen, 1997). So, LHTL enables athletes to benefit from both the effects of chronic exposure to altitude and from maintaining a level of training intensity close to that used typically at sea level (Levine and Stray-Gundersen, 1997). In this initial study, Levine and Stray-Gundersen (1997) described significant hematological adaptations (notably elevated erythropoietin, hemoglobin, and hematocrit) associated with a gain in performance. Several follow-up studies gave essentially similar results (Hahn et al., 2001; Stray-Gundersen et al., 2001; Dehnert et al., 2002; Chapman et al., 2014) although other researchers observed no (or only small) hematological changes after LHTL (Ashenden et al., 1999, 2000). It is well-known that endurance performance (i.e., $\mathrm{VO}_{2} \mathrm{max}$ ) does not depend solely on hematological parameters. Indeed, peripheral factors like exercise economy and/or buffering capacity (Gore et al., 2001, 2007; Saunders et al., 2004) might also contribute to postLHTL performance. The initial LHTL model has evolved, with the development of new devices for artificially creating altitude conditions (i.e., normobaric hypoxia). At present, athletes no longer need to go up into the mountains to find a hypoxic environment. Regardless of the simulation method, not all endurance athletes respond in the same way to altitude training, and considerable inter-individual variations in responses have been documented (Chapman, 2013; Nummela et al., 2021).

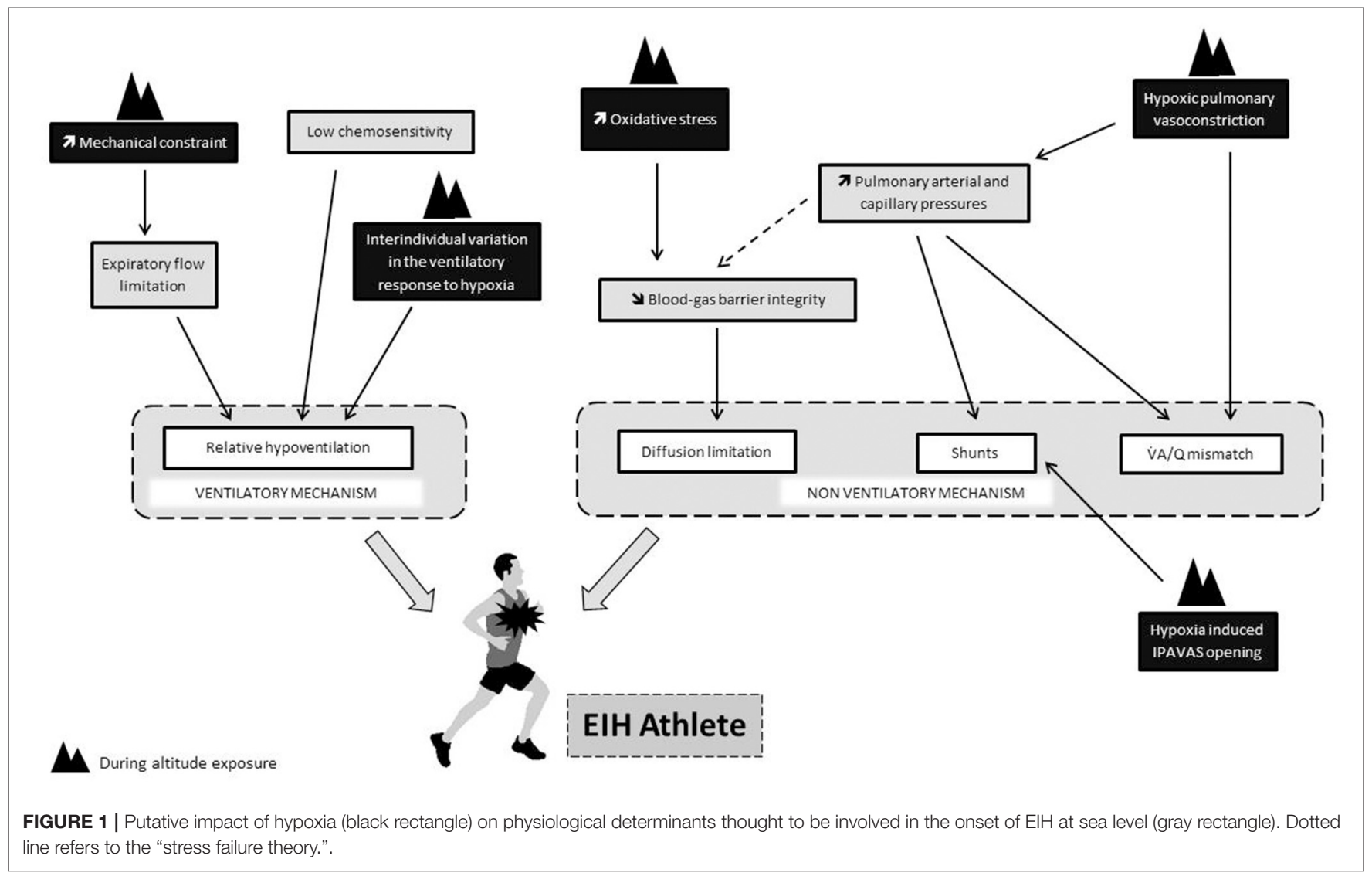


In this context, several methodological, training-related, and physiological factors have been identified but the putative impact of EIH on individual responses has never been investigated. Only a study evaluated the impact of intermittent hypoxia for 10 days $\left(90 \mathrm{~min} \cdot \mathrm{day}^{-1}\right.$, with $\mathrm{FiO}_{2}$ giving a $\mathrm{SaO}_{2}$ of $80 \%$ ) on $\mathrm{EIH}$ athletes while others followed the same protocol under normoxic conditions (Marshall et al., 2008). The researchers found that exposure to intermittent hypoxia reduced the severity of EIH ( $94 \%$ after exposure, compared with $91 \%$ before). The increase in $\mathrm{SaO}_{2}$ might have been mediated by increased chemosensitivity at altitude, which in turn might increase hyperventilation (Katayama et al., 2001; Ainslie et al., 2003). Indeed, EIH athletes are thought to be poorly chemosensitive (Harms and Stager, 1995; Constantini et al., 2017; Granger et al., 2020). However, no improvements in $\mathrm{VO}_{2} \mathrm{max}$ or performance were reported. Thus, the interactions between EIH and altitude during the acclimatization phase remain to be explored.

\section{NEW RESULTS AND POTENTIAL INTERACTION BETWEEN EIH AND CHRONIC EXPOSURE TO ALTITUDE}

There are few studies on this topic. It was recently reported that $\mathrm{EIH}$ athletes presented lower resting and maximal $\mathrm{SpO}_{2}$ values after 5 days of exposure to $2400 \mathrm{~m}$ (Durand et al., 2019). During this prolonged hypoxia, EIH athletes maintained a greater maximal cardiac output (vs. NEIH athletes), suggesting specific cardiovascular adaptations that enabled the achievement of the same $\mathrm{VO}_{2}$ max. During the same protocol, EIH athletes exhibit an exacerbated oxidative stress at sea level compared to NEIH athletes while there was no between group difference after 1 day of exposure (Raberin et al., 2021). This result suggests that the impact of EIH on oxidative stress was blunted by acute altitude. However after 5 days of exposure, the reappearance of the between group difference suggest that EIH athletes may elicit a greater ventilatory acclimatization due to higher oxidative stress, since oxidative stress has been shown to modulate the hypoxic ventilatory response (Pialoux et al., 2009). However, the study failed to conclude on a role of oxidative stress at the onset of EIH due to its impact on pulmonary endothelial permeability (Nielsen, 2003).

One could also suspect that the mechanisms at the origin of EIH at sea level could be exacerbated during prolonged altitude exposure. The low chemosensitivity of EIH athletes could impact the kinetic of ventilatory acclimatation and be at the onset of a greater relative hypoventilation during exercise in hypoxia. An exacerbation of the ventilation/perfusion mismatch and extravascular pulmonary fluid movements may also occur during prolonged exposure. Indeed, pulmonary vessels constrict in response to alveolar hypoxia, this phenomenon known as hypoxic pulmonary vasoconstriction (HPV) aims to divert blood to better-oxygenated lung segments, thereby optimizing ventilation/perfusion matching and systemic $\mathrm{O}_{2}$ delivery (Swenson, 2013). HPV is known to persist during prolonged exposure to hypoxia and to increase pulmonary arterial pressure and pulmonary arterial resistance (Raberin et al., 2019b). These hemodynamic changes might be triggered intrapulmonary arteriovenous anastomosis (IPAVAS) recruitment leading to an arterial $\mathrm{O}_{2}$ desaturation due to shunt. Some evidences show that hypoxia could have a role in the opening of IPAVAS but whether $\mathrm{O}_{2}$ tension regulates IPAVAS remains unclear (Laurie et al., 2010; Lovering et al., 2015). Further studies are needed to understand how EIH changes during chronic exposure to altitude. Finally, the Figure 1 provides a summary of the physiological determinants of EIH in relation to the modalities of exposure to hypoxia.

\section{EIH: FROM PHYSIOLOGICAL CONSIDERATION TO TRAINING MONITORING}

The roles of EIH following diffusion limitation (Chapman et al., 1999), excessive work of breathing (Amann et al., 2007), and increased pulmonary vascular resistance and arterial pressure (Eldridge et al., 2006; Faoro et al., 2009) are clear and raise the question of whether EIH has an additional role in the context of hypoxic training.

However, it seems essential to better understand EIH in ecological condition since athletes rarely reach maximal aerobic capacities during training. In addition, the course of EIH during altitude/hypoxic training and its consequences on training goals should be investigated. We can suggest different avenues to develop this knowledge: (i) monitor $\mathrm{SpO}_{2}$ during ecological training session to understand the frequency, duration, and severity of the hypoxemic episode and which kind of training might induce significant hypoxemia, (ii) evaluate whether EIH could impair or facilitate acclimatization to altitude and thereafter, (iii) investigate the putative role of EIH in the great variability of the response to altitude/hypoxia training whatever the method. In order to collect and analyze the large amounts of data and their interaction, openness to the science complex system is essential. In recent years, mathematics has been increasingly used in physiology (Lloyd et al., 2016; Pereira et al., 2018). The integration of sports science analysis with complex networks is called "complex sports analytics" and makes it possible to approach complex network structures as a very promising model prediction tool.

Individualization of the altitude dose is well-known to be the key of altitude/hypoxic training to ultimately reduce inter-individual variability. In the context, monitor the EIH during training has to be considered as a main factor of this individualization to find the best practice to increase performance.

\section{AUTHOR CONTRIBUTIONS}

The original conception of the work was conducted and the manuscript was drafted by FD and AR. Both authors read and approved the final manuscript. 


\section{REFERENCES}

Ainslie, P. N., Kolb, J. C., Ide, K., and Poulin, M. J. (2003). Effects of five nights of normobaric hypoxia on the ventilatory responses to acute hypoxia and hypercapnia. Respir. Physiol. Neurobiol. 138, 193-204. doi: 10.1016/S1569-9048(03)00190-3

Alis, R., Sanchis-Gomar, F., Ferioli, D., La Torre, A., Blesa, J. R., and Romagnoli, M. (2015). Exercise effects on erythrocyte deformability in exercise-induced arterial hypoxemia. Int. J. Sports Med. 36, 286-291. doi: 10.1055/s-0034-1394395

Amann, M. (2012). Pulmonary system limitations to endurance exercise performance in humans. Exp. Physiol. 97, 311-318. doi: 10.1113/expphysiol.2011.058800

Amann, M., Pegelow, D. F., Jacques, A. J., and Dempsey, J. A. (2007). Inspiratory muscle work in acute hypoxia influences locomotor muscle fatigue and exercise performance of healthy humans. Am. J. Physiol. Regul. Integr. Comp. Physiol. 293, R2036-R2045. doi: 10.1152/ajpregu.00442.2007

Ashenden, M. J., Gore, C. J., Dobson, G. P., Boston, T. T., Parisotto, R., Emslie, K. R., et al. (2000). Simulated moderate altitude elevates serum erythropoietin but does not increase reticulocyte production in well-trained runners. Eur. J. Appl. Physiol. 81, 428-435. doi: 10.1007/s004210050064

Ashenden, M. J., Gore, C. J., Martin, D. T., Dobson, G. P., and Hahn, A. G. (1999). Effects of a 12-day "live high, train low" camp on reticulocyte production and haemoglobin mass in elite female road cyclists. Eur. J. Appl. Physiol. Occup. Physiol. 80, 472-478. doi: 10.1007/s004210050620

Benoit, H., Busso, T., Castells, J., Geyssant, A., and Denis, C. (2003). Decrease in peak heart rate with acute hypoxia in relation to sea level $\mathrm{VO}(2 \mathrm{max})$. Eur. J. Appl. Physiol. 90, 514-519. doi: 10.1007/s00421-003-0899-y

Brooks, G. A., and Mercier, J. (1994). Balance of carbohydrate and lipid utilization during exercise: the "crossover" concept. J. Appl. Physiol. (1985) 76, 2253-2261. doi: 10.1152/jappl.1994.76.6.2253

Chapman, R. F. (2013). The individual response to training and competition at altitude. Br. J. Sports Med. 47, i40-i44. doi: 10.1136/bjsports-2013-092837

Chapman, R. F., Emery, M., and Stager, J. M. (1999). Degree of arterial desaturation in normoxia influences VO2max decline in mild hypoxia. Med. Sci. Sports Exerc. 31, 658-663. doi: 10.1097/00005768-199905000-00006

Chapman, R. F., Laymon Stickford, A. S., Lundby, C., and Levine, B. D. (2014). Timing of return from altitude training for optimal sea level performance. $J$. Appl. Physiol. 116, 837-843. doi: 10.1152/japplphysiol.00663.2013

Chapman, R. F., Stager, J. M., Tanner, D. A., Stray-Gundersen, J., and Levine, B. D. (2011). Impairment of 3000-m run time at altitude is influenced by arterial oxyhemoglobin saturation. Med. Sci. Sports Exerc. 43, 1649-1656. doi: 10.1249/MSS.0b013e318211bf45

Connes, P., and Boucher, J. H. (2010). Echinocytosis in athletes with exercise-induced hypoxemia. Clin. Hemorheol. Microcirc. 44, 107-114. doi: 10.3233/CH-2010-1258

Connes, P., Bouix, D., Durand, F., Kippelen, P., Mercier, J., Prefaut, C., et al. (2004a). Is hemoglobin desaturation related to blood viscosity in athletes during exercise? Int. J. Sports Med. 25, 569-574. doi: 10.1055/s-2004-821118

Connes, P., Bouix, D., Py, G., Caillaud, C., Kippelen, P., Brun, J.-F., et al. (2004b). Does exercise-induced hypoxemia modify lactate influx into erythrocytes and hemorheological parameters in athletes? J. Appl. Physiol. 97, 1053-1058. doi: 10.1152/japplphysiol.00993.2003

Constantini, K., Tanner, D. A., Gavin, T. P., Harms, C. A., Stager, J. M., and Chapman, R. F. (2017). Prevalence of exercise-induced arterial hypoxemia in distance runners at sea level. Med. Sci. Sports Exerc. 49, 948-954. doi: 10.1249/MSS.0000000000001193

Dehnert, C., Hütler, M., Liu, Y., Menold, E., Netzer, C., Schick, R., et al. (2002). Erythropoiesis and performance after two weeks of living high and training low in well trained triathletes. Int. J. Sports Med. 23, 561-566. doi: $10.1055 / \mathrm{s}-2002-35533$

Dempsey, J. A., Hanson, P. G., and Henderson, K. S. (1984). Exercise-induced arterial hypoxaemia in healthy human subjects at sea level. J. Physiol. 355, 161-175. doi: 10.1113/jphysiol.1984.sp015412

Dempsey, J. A., La Gerche, A., and Hull, J. H. (2020). Is the healthy respiratory system built just right, overbuilt, or underbuilt to meet the demands imposed by exercise? J. Appl. Physiol. (1985) 129, 1235-1256. doi: 10.1152/japplphysiol.00444.2020
Dempsey, J. A., and Wagner, P. D. (1999). Exercise-induced arterial hypoxemia. J. Appl. Physiol. 87, 1997-2006. doi: 10.1152/jappl.1999.87.6.1997

Derchak, P. A., Stager, J. M., Tanner, D. A., and Chapman, R. F. (2000). Expiratory flow limitation confounds ventilatory response during exercise in athletes. Med. Sci. Sports Exerc. 32, 1873-1879. doi: 10.1097/00005768-200011000-00009

Dominelli, P. B., Foster, G. E., Dominelli, G. S., Henderson, W. R., Koehle, M. S., McKenzie, D. C., et al. (2013). Exercise-induced arterial hypoxaemia and the mechanics of breathing in healthy young women. J. Physiol. (Lond.) 591, 3017-3034. doi: 10.1113/jphysiol.2013.252767

Dominelli, P. B., and Sheel, A. W. (2018). Exercise-induced arterial hypoxemia; some answers, more questions. Appl. Physiol. Nutr. Metab. 44, 571-579 doi: 10.1139/apnm-2018-0468

Durand, F., Gaston, A.-F., Vicenzi, M., Deboeck, G., Subirats, E., and Faoro, V. (2020). Noninvasive pulmonary hemodynamic evaluation in athletes with exercise-induced hypoxemia. Chest 157, 1568-1578. doi: 10.1016/j.chest.2020.01.037

Durand, F., Mucci, P., and Préfaut, C. (2000). Evidence for an inadequate hyperventilation inducing arterial hypoxemia at submaximal exercise in all highly trained endurance athletes. Med. Sci. Sports Exerc. 32, 926-932. doi: 10.1097/00005768-200005000-00008

Durand, F., Raberin, A., Meric, H., Mucci, P., and Lopez Ayerbe, J. (2019). "Exercise-induced hypoxemia leads to specific adaptations in cardiovascular system during acclimatization to moderate hypoxia," in Book of abstracts-24th Annual Congress of the European College of Sport Science (Prague: European College of Sport Science), 237. Available online at: https://www.dropbox.com/ s/7z3xr5rblm51069/Prague_BOA_Web.pdf?dl=0 (accessed January 29, 2021).

Eldridge, M. W., Braun, R. K., Yoneda, K. Y., and Walby, W. F. (2006). Effects of altitude and exercise on pulmonary capillary integrity: evidence for subclinical high-altitude pulmonary edema. J. Appl. Physiol. 100, 972-980. doi: 10.1152/japplphysiol.01048.2005

Faoro, V., Boldingh, S., Moreels, M., Martinez, S., Lamotte, M., Unger, P., et al. (2009). Bosentan decreases pulmonary vascular resistance and improves exercise capacity in acute hypoxia. Chest 135, 1215-1222. doi: 10.1378/chest.08-2222

Gaston, A.-F., Durand, F., Roca, E., Doucende, G., Hapkova, I., and Subirats, E. (2016). Exercise-induced hypoxaemia developed at sea-level influences responses to exercise at moderate altitude. PLoS ONE 11:e0161819. doi: 10.1371/journal.pone.0161819

Gavin, T. P., Derchak, P. A., and Stager, J. M. (1998). Ventilation's role in the decline in VO2max and $\mathrm{SaO} 2$ in acute hypoxic exercise. Med. Sci. Sports Exerc. 30, 195-199. doi: 10.1097/00005768-199802000-00004

Gore, C. J., Clark, S. A., and Saunders, P. U. (2007). Nonhematological mechanisms of improved sea-level performance after hypoxic exposure. Med. Sci. Sports Exerc. 39, 1600-1609. doi: 10.1249/mss.0b013e3180de49d3

Gore, C. J., Hahn, A. G., Aughey, R. J., Martin, D. T., Ashenden, M. J., Clark, S. A., et al. (2001). Live high:train low increases muscle buffer capacity and submaximal cycling efficiency. Acta Physiol. Scand. 173, 275-286. doi: 10.1046/j.1365-201X.2001.00906.x

Granger, E. A., Cooper, T. K., Hopkins, S. R., McKenzie, D. C., and Dominelli, P. (2020). Peripheral chemoresponsiveness during exercise in male athletes with exercise-induced arterial hypoxaemia. Exp. Physiol. 105, 1960-1970. doi: 10.1113/EP088639

Grataloup, O., Busso, T., Castells, J., Denis, C., and Benoit, H. (2007). Evidence of decrease in peak heart rate in acute hypoxia: effect of exercise-induced arterial hypoxemia. Int. J. Sports Med. 28, 181-185. doi: 10.1055/s-2006-924216

Grataloup, O., Prieur, F., Busso, T., Castells, J., Favier, F. B., Denis, C., et al. (2005). Effect of hyperoxia on maximal O2 uptake in exerciseinduced arterial hypoxaemic subjects. Eur. J. Appl. Physiol. 94, 641-645. doi: 10.1007/s00421-005-1361-0

Guenette, J. A., Diep, T. T., Koehle, M. S., Foster, G. E., Richards, J. C., and Sheel, A. W. (2004). Acute hypoxic ventilatory response and exercise-induced arterial hypoxemia in men and women. Respir. Physiol. Neurobiol. 143, 37-48. doi: 10.1016/j.resp.2004.07.004

Hahn, A. G., Gore, C. J., Martin, D. T., Ashenden, M. J., Roberts, A. D., and Logan, P. A. (2001). An evaluation of the concept of living at moderate altitude and training at sea level. Comp. Biochem. Physiol. A Mol. Integr. Physiol. 128, 777-789. doi: 10.1016/S1095-6433(01)00 283-5 
Harms, C. A., McClaran, S. R., Nickele, G. A., Pegelow, D. F., Nelson, W. B., and Dempsey, J. A. (2000). Effect of exercise-induced arterial O2 desaturation on VO2max in women. Med. Sci. Sports Exerc. 32, 1101-1108. doi: 10.1097/00005768-200006000-00010

Harms, C. A., and Stager, J. M. (1995). Low chemoresponsiveness and inadequate hyperventilation contribute to exercise-induced hypoxemia. J. Appl. Physiol. 79, 575-580. doi: 10.1152/jappl.1995.79.2.575

Holmgren, A., and McIlroy, M. B. (1964). Effect of temperature on arterial blood gas tensions and $\mathrm{pH}$ during exercise. J. Appl. Physiol. 19, 243-245. doi: 10.1152/jappl.1964.19.2.243

Hopkins, S. R., and McKenzie, D. C. (1989). Hypoxic ventilatory response and arterial desaturation during heavy work. J. Appl. Physiol. 67, 1119-1124. doi: 10.1152/jappl.1989.67.3.1119

Katayama, K., Sato, Y., Morotome, Y., Shima, N., Ishida, K., Mori, S., et al. (2001). Intermittent hypoxia increases ventilation and $\mathrm{Sa}(\mathrm{O} 2)$ during hypoxic exercise and hypoxic chemosensitivity. J. Appl. Physiol. 90, 1431-1440. doi: 10.1152/jappl.2001.90.4.1431

Kyparos, A., Riganas, C., Nikolaidis, M. G., Sampanis, M., Koskolou, M. D., Grivas, G. V., et al. (2012). The effect of exercise-induced hypoxemia on blood redox status in well-trained rowers. Eur. J. Appl. Physiol. 112, 2073-2083. doi: 10.1007/s00421-011-2175-X

Laurie, S. S., Yang, X., Elliott, J. E., Beasley, K. M., and Lovering, A. T. (2010). Hypoxia-induced intrapulmonary arteriovenous shunting at rest in healthy humans. J. Appl. Physiol. 109, 1072-1079. doi: 10.1152/japplphysiol.00150.2010

Legrand, R., Ahmaidi, S., Moalla, W., Chocquet, D., Marles, A., Prieur, F., et al. (2005). O2 arterial desaturation in endurance athletes increases muscle deoxygenation. Med. Sci. Sports Exerc. 37, 782-788. doi: 10.1249/01.MSS.0000161806.47058.40

Levine, B. D., and Stray-Gundersen, J. (1997). "Living high-training low": effect of moderate-altitude acclimatization with low-altitude training on performance. J. Appl. Physiol. 83, 102-112. doi: 10.1152/jappl.1997.83.1.102

Lloyd, A., Raccuglia, M., Hodder, S., and Havenith, G. (2016). Interaction between environmental temperature and hypoxia on central and peripheral fatigue during high-intensity dynamic knee extension. J. Appl. Physiol. (1985) 120, 567-579. doi: 10.1152/japplphysiol.00876.2015

Lovering, A. T., Duke, J. W., and Elliott, J. E. (2015). Intrapulmonary arteriovenous anastomoses in humans-response to exercise and the environment. J. Physiol. 593:507. doi: 10.1113/jphysiol.2014.275495

Marshall, H. C., Hamlin, M. J., Hellemans, J., Murrell, C., Beattie, N., Hellemans, I., et al. (2008). Effects of intermittent hypoxia on $\mathrm{SaO}(2)$, cerebral, and muscle oxygenation during maximal exercise in athletes with exercise-induced hypoxemia. Eur. J. Appl. Physiol. 104, 383-393. doi: 10.1007/s00421-007-0616-3

Millet, G. P., Roels, B., Schmitt, L., Woorons, X., and Richalet, J. P. (2010). Combining hypoxic methods for peak performance. Sports Med. 40, 1-25. doi: 10.2165/11317920-000000000-00000

Mollard, P., Bourdillon, N., Letournel, M., Herman, H., Gibert, S., Pichon, A., et al. (2010). Validity of arterialized earlobe blood gases at rest and exercise in normoxia and hypoxia. Respir. Physiol. Neurobiol. 172, 179-183. doi: 10.1016/j.resp.2010.05.017

Mucci, P., Durand, F., Lebel, B., Bousquet, J., and Préfaut, C. (2000). Interleukins 1-beta, -8 , and histamine increases in highly trained, exercising athletes. Med. Sci. Sports Exerc. 32, 1094-1100. doi: 10.1097/00005768-200006000-00009

Mucci, P., Prioux, J., Hayot, M., Ramonatxo, M., and Préfaut, C. (1998). Ventilation response to $\mathrm{CO} 2$ and exercise-induced hypoxaemia in master athletes. Eur. J. Appl. Physiol. Occup. Physiol. 77, 343-351. doi: $10.1007 / \mathrm{s} 004210050343$

Nielsen, H. B. (2003). Arterial desaturation during exercise in man: implication for O2 uptake and work capacity. Scand. J. Med. Sci. Sports 13, 339-358. doi: 10.1046/j.1600-0838.2003.00325.x

Nummela, A., Eronen, T., Koponen, A., Tikkanen, H., and Peltonen, J. E. (2021). Variability in hemoglobin mass response to altitude training camps. Scand. J. Med. Sci. Sports 31, 44-51. doi: 10.1111/sms.13804

Pereira, V. H., Gobatto, C. A., Lewis, T. G., Ribeiro, L. F. P., Beck, W. R., Dos Reis, I. G. M., et al. (2018). Computational and complex network modeling for analysis of sprinter athletes' performance in track field tests. Front. Physiol. 9:843. doi: 10.3389/fphys.2018.00843

Pialoux, V., Brugniaux, J. V., Fellmann, N., Richalet, J.-P., Robach, P., Schmitt, L., et al. (2009). Oxidative stress and HIF-1 alpha modulate hypoxic ventilatory responses after hypoxic training on athletes. Respir. Physiol. Neurobiol. 167, 217-220. doi: 10.1016/j.resp.2009.04.012

Powers, S. K., Dodd, S., Lawler, J., Landry, G., Kirtley, M., McKnight, T., et al. (1988). Incidence of exercise induced hypoxemia in elite endurance athletes at sea level. Eur. J. Appl. Physiol. Occup. Physiol. 58, 298-302. doi: 10.1007/BF00417266

Powers, S. K., Dodd, S., Woodyard, J., Beadle, R. E., and Church, G. (1984). Haemoglobin saturation during incremental arm and leg exercise. Br. J. Sports Med. 18, 212-216. doi: 10.1136/bjsm.18.3.212

Powers, S. K., Martin, D., and Dodd, S. (1993). Exercise-induced hypoxaemia in elite endurance athletes. Incidence, causes and impact on VO2max. Sports Med. 16, 14-22. doi: 10.2165/00007256-199316010-00003

Préfaut, C., Anselme, F., Caillaud, C., and Massé-Biron, J. (1994). Exerciseinduced hypoxemia in older athletes. J. Appl. Physiol. 76, 120-126. doi: 10.1152/jappl.1994.76.1.120

Préfaut, C., Bourgouin-Karaouni, D., Ramonatxo, M., Michel, F. B., and Macabies, J. (1988). A one year double blind follow-up of blood gas tensions and haemodynamics in almitrine bismesylate therapy. Eur. Respir. J. 1, 41-50.

Prefaut, C., Durand, F., Mucci, P., and Caillaud, C. (2000). Exerciseinduced arterial hypoxaemia in athletes: a review. Sports Med. 30, 47-61. doi: 10.2165/00007256-200030010-00005

Raberin, A., Meric, H., Mucci, P., Lopez Ayerbe, J., and Durand, F. (2019a). Muscle and cerebral oxygenation during exercise in athletes with exercise-induced hypoxemia: a comparison between sea level and acute moderate hypoxia. Eur. J. Sport Sci. 20, 803-812. doi: 10.1080/17461391.2019.1669717

Raberin, A., Nader, E., Ayerbe, J. L., Mucci, P., Connes, P., and Durand, F. (2019b). Evolution of blood rheology and its relationship to pulmonary hemodynamic during the first days of exposure to moderate altitude. Clin. Hemorheol. Microcirc. 74, 201-208. doi: 10.3233/CH-190671

Raberin, A., Nader, E., Lopez Ayerbe, J., Alfonsi, G., Mucci, P., Rytz, C. L., et al. (2021). Pro-Oxidant/Antioxidant balance during a prolonged exposure to moderate altitude in athletes exhibiting exercise-induced hypoxemia at sea-level. Life 11:228. doi: 10.3390/life11030228

Richards, J. C., McKenzie, D. C., Warburton, D. E. R., Road, J. D., and Sheel, A. W. (2004). Prevalence of exercise-induced arterial hypoxemia in healthy women. Med. Sci. Sports Exerc. 36, 1514-1521. doi: 10.1249/01.MSS.0000139898.30804.60

Riganas, C., Papadopoulou, Z., Margaritelis, N. V., Christoulas, K., and Vrabas, I. S. (2019). Inspiratory muscle training effects on oxygen saturation and performance in hypoxemic rowers: effect of sex. J. Sports Sci. 37, 2513-2521. doi: 10.1080/02640414.2019.1646582

Romer, L. M., Haverkamp, H. C., Lovering, A. T., Pegelow, D. F., and Dempsey, J. A. (2006). Effect of exercise-induced arterial hypoxemia on quadriceps muscle fatigue in healthy humans. Am. J. Physiol. Regul. Integr. Comp. Physiol. 290, R365-R375. doi: 10.1152/ajpregu.00332.2005

Saunders, P. U., Telford, R. D., Pyne, D. B., Cunningham, R. B., Gore, C. J., Hahn, A. G., et al. (2004). Improved running economy in elite runners after 20 days of simulated moderate-altitude exposure. J. Appl. Physiol. (1985) 96, 931-937. doi: 10.1152/japplphysiol.00725.2003

Scroop, G. C., and Shipp, N. J. (2010). Exercise-induced hypoxemia: fact or fallacy? Med. Sci. Sports Exerc. 42, 120-126. doi: 10.1249/MSS.0b013e3181a d0117

Sheel, A. W., Edwards, M. R., Hunte, G. S., and McKenzie, D. C. (2001). Influence of inhaled nitric oxide on gas exchange during normoxic and hypoxic exercise in highly trained cyclists. J. Appl. Physiol. 90, 926-932. doi: 10.1152/jappl.2001.90.3.926

Sheel, A. W., Edwards, M. R., and McKenzie, D. C. (2000). Relationship between decreased oxyhaemoglobin saturation and exhaled nitric oxide during exercise. Acta Physiol. Scand. 169, 149-156. doi: 10.1046/j.1365-201x.2000.00729.x

St Croix, C. M., Harms, C. A., McClaran, S. R., Nickele, G. A., Pegelow, D. F., Nelson, W. B., et al. (1998). Effects of prior exercise on exerciseinduced arterial hypoxemia in young women. J. Appl. Physiol. 85, 1556-1563. doi: 10.1152/jappl.1998.85.4.1556

Stewart, I. B., Labreche, J. M., and McKenzie, D. C. (2003). Effect of a long- and short-acting beta2-agonist on exercise-induced arterial hypoxemia. Med. Sci. Sports Exerc. 35, 603-607. doi: 10.1249/01.MSS.0000058439.11005.38

Stewart, I. B., and Pickering, R. L. (2007). Effect of prolonged exercise on arterial oxygen saturation in athletes susceptible to exercise-induced hypoxemia. 
Scand. J. Med. Sci. Sports 17, 445-451. doi: 10.1111/j.1600-0838.2006. 00563.x

Stray-Gundersen, J., Chapman, R. F., and Levine, B. D. (2001). "Living high-training low" altitude training improves sea level performance in male and female elite runners. J. Appl. Physiol. (1985) 91, 1113-1120. doi: 10.1152/jappl.2001.91.3.1113

Swenson, E. R. (2013). Hypoxic pulmonary vasoconstriction. High Alt. Med. Biol. 14, 101-110. doi: 10.1089/ham.2013.1010

Verges, S., Flore, P., Favre-Juvin, A., Lévy, P., and Wuyam, B. (2005). Exhaled nitric oxide during normoxic and hypoxic exercise in endurance athletes. Acta Physiol. Scand. 185, 123-131. doi: 10.1111/j.1365-201X.2005.01475.x
Conflict of Interest: The authors declare that the research was conducted in the absence of any commercial or financial relationships that could be construed as a potential conflict of interest.

Copyright $\odot 2021$ Durand and Raberin. This is an open-access article distributed under the terms of the Creative Commons Attribution License (CC BY). The use, distribution or reproduction in other forums is permitted, provided the original author(s) and the copyright owner(s) are credited and that the original publication in this journal is cited, in accordance with accepted academic practice. No use, distribution or reproduction is permitted which does not comply with these terms. 